\title{
A LISBOA MEDIEVAL DOS VISITANTES E DOS HISTORIADORES
}

\author{
SUSANI SILVEIRA LEMOS FRANÇA \\ Universidade do Estado de São Paulo (Franca)
}

\section{RESUMO}

O presente artigo põe em confronto a perspectiva de cronistas portugueses quatrocentistas e viajantes estrangeiros que passaram por Lisboa no século $\mathrm{XV}$, com a finalidade de mostrar como esses escritos foram decisivos para fazer da cidade a "cabeça" de Portugal, já que o passado que selecionaram para tornar lembrado ajudou a traçar o passado que se consolidou como o "verdadeiro" passado de Lisboa. Com pesos diferenciados, cronistas e viajantes são as peças-chave na configuração da imagem de Lisboa e de uma história de Lisboa. Uma imagem e uma história que não devem ser ingenuamente opostas a um conjecturado real, mas, antes, devem ser vistas como formas narrativas de dar sentido a experiências difusas. Cronistas e viajantes do século XV pintam uma Lisboa que ainda não se anunciava como a dirigente das navegações para Oriente e Ocidente, como virá a defini-la o cronista Damião de Góis no século XVI e como o seguirão viajantes estrangeiros, mas que já era prenunciada como "cidade grandíssima e cabeça de Portugal".

PalAVRAS-ChAVE: Lisboa; Idade Média; Cronistas; Viajantes.

\section{ABSTRACT}

This article compares the points of view of $15^{\text {th }}$-century Portuguese chroniclers and travelers who passed through Lisbon in that same century, to show how these writings were decisive in making it the main city of Portugal, since the past they had selected to be remembered helped to shape what has become the "true" history of Lisbon. With different emphases, chroniclers and travelers have been the key elements in shaping the image of Lisbon and its history. A picture and history should be seen as narrative forms giving meaning to diffuse experience, and should not be naively opposite to a conjectured reality. Chroniclers and travelers from the $15^{\text {th }}$ century painted the picture of a Lisbon that had not yet been announced as the heart of navigation to the East and West, though it was soon to be defined as such by the chronicler Damião de Góis in the $16^{\text {th }}$ century, followed by foreign travelers, despite the fact that it had already been heralded as the "greatest city and center of Portugal".

KEYWORDS: Lisbon; Middle Age; Chroniclers; Travelers. 
Em viagem feita à Espanha no ano de 1512, Francesco Guicciardini, célebre historiador e estadista italiano, ${ }^{1}$ embaixador de Florença junto à corte do Rei Católico, D. Fernando, legou-nos uma relação de viagem em que, menos do que com as paisagens e gentes que encontra, mostra-se mais preocupado com o novo Estado que acabava de se formar pela junção dos reinos de Aragão e Castela - graças ao casamento de Isabel de Castela e Fernando de Aragão. 0 notável escritor, reconhecido como um dos principais do seu tempo, pouco diz sobre as cidades ou sobre as configurações geográficas da Península. Todavia, faz uma referência a Lisboa que se distingue bastante de outras que caracterizam os relatos de viagem do século anterior, quando ainda eram reduzidos os passos da expansão ultramarina, ou melhor, quando ainda não se tinha por certo, como Bartolomeu Marchioni ${ }^{2}$ afirmou no início do século XVI, que $\mathrm{o}$ rei português tinha descoberto "um novo mundo". ${ }^{3} \mathrm{O}$ embaixador florentino descreve Portugal como província pequena, "mais conhecida pelo grande comércio de mercadores que há em Lisboa" e pelas regiões de Calicute descobertas pelos portugueses. ${ }^{4}$

$\mathrm{Se}$, porém, é essa a ênfase conferida à Lisboa do século XVI, o mesmo não se nota no que diz respeito à do século anterior, quando ainda Portugal se situava no polo oposto ao do interesse dos viajantes de diversas partes, atentos às conquistas a leste, ou melhor, quando ainda o centro do comércio marítimo se mantinha no Báltico, no Mar do Norte e no Mar Mediterrâneo. Apenas no século XVI, com o protagonismo comercial do Atlântico, cidades como Lisboa, Sevilha, Cádiz e Amsterdã ganharam destaque e desenvolvimento, e contribuíram para fragilizar cidades como Lübeck, Veneza e Gênova. ${ }^{5}$ Um dos mais completos relatos de viagens pela Espanha e por Portugal do século $\mathrm{XV}$, por exemplo, é o relato do nobre boêmio Leon de Rosmital de Blatna, que relata sua viagem realizada entre 1465 e 1467 . O nobre, preocupado, como outros viajantes do seu tempo, em mencionar certas cidades por onde passou, sobretudo para dar a conhecer seus percursos e seus feitos de viagem, refere 0 posicionamento geográfico dessas e certas construções que as caracterizam, em especial os castelos. Tendo recebido do conde D. Fernando, $2^{\circ}$ Duque de

\footnotetext{
${ }^{1}$ Autor da História da Itália, cuja obra ajudou a alimentar os "debates sobre a natureza da república que dominaram a cena intelectual florentina e italiana no começo do século XVI". BIGNOTTO, Newton. Republicanismo e realismo: um perfil de Francesco Guicciardini. Belo Horizonte: Editora da UFMG, 2006, p. 11.

${ }^{2}$ Negociante florentino radicado em Lisboa, que atuou como importante colaborador dos reis de Portugal desde D. João II. COUTO, Jorge. O Achamento da Terra de Vera Cruz. Revista de Letras e Culturas Lusófonas. n. 8, Janeiro-Março de 2000. Disponível em: http://www.institutocamoes.pt/revista/achamentvc.htm. Acesso em 12/06/2010.

${ }^{3}$ Citado por ANDRADE, A. A. Banha de. Mundos novos do mundo. Panorama da difusão pela Europa de notícias dos descobrimentos geográficos portugueses. Lisboa: Junta de Investigações do Ultramar, 1972, p. 235.

${ }^{4}$ Viajes por España de Jorge de Einghen, del baron Leon de Rosmithal de Blatna, de Francisco Guicciardini y de Andrés Navajero. Traducidos, anotados y con una introducción por D. Antonio María Fabié, de la Academia de la Historia. Madrid: Librería de los Bibliófilos - Fernando Fé, 1879 , p.195 (tradução minha).

${ }^{5}$ Como sintetiza Oliveira Marques, não se pode falar da Lisboa medieval como cidade mercantil à maneira de Veneza ou Bruges, dado o peso da agricultura e da pesca na dinâmica da cidade, bem como certa autossuficiência na produção alimentícia. OLIVEIRA MARQUES, A. H. Novos ensaios de história medieval portuguesa. Lisboa: Editorial Presença, 1988, p. 85-86.
} 
Bragança, Marquês de Vila Viçosa e Conde de Barcelos, carta para transitar por Portugal sem pagar pedágios, peitas ou quaisquer outros tributos, ${ }^{6}$ o viajante passa, entre outras cidades, por Guimarães, Braga, Porto e Lisboa, da qual diz apenas ser "cidade grandíssima e cabeça de Portugal", 7 a "principal cidade do reino de Portugal". Poucas referências, pois, acrescidas de informações sobre a cobrança de impostos sobre o vinho por parte do irmão do rei D. Afonso, D. Fernando, $1^{0}$ Duque de Beja e $2^{\circ}$ Duque de Viseu. ${ }^{8}$ Já sobre outras cidades, 0 viajante é um pouco mais específico, não apenas no que diz respeito à posição e configurações geográficas, mas também no que se refere às circunstâncias históricas que as envolvem. Acerca do Porto, por exemplo, refere a ancoragem de naves com mercadorias de outros mares em quantidade como nunca tinha visto em "nenhuma outra cidade marítima" e assinala a presença de "infiéis" comercializados pelos cristãos, ${ }^{9}$ "porque todos os anos chegam [ali] cativos muitos milhares deles". Coimbra, por sua vez, também merece mais considerações que Lisboa, sendo apresentada no relato como situada "na fralda de uma colina" e como cidade não muito grande, mas "mui bela e bem provida", nas proximidades da qual havia um "belo monastério". E Braga, como Lisboa, é apresentada como outra "cabeça do reino de Portugal", na qual o viajante encontrou o Rei com sua corte e da qual refere a existência de um "palácio episcopal e outro ducal [...], ambos magníficos", e ainda a existência de uma igreja com uma "bela portada de pedra". ${ }^{10}$

Não são muitas mais as indicações sobre Lisboa ou sobre as cidades portuguesas de relativa importância que aparecem em outros relatos do século XV. Viajantes como o nuremberguense Gabriel Tetzel ${ }^{11}$ e o cavaleiro da Suábia Jorge de Einghen não acrescentam grandes dados sobre as cidades portuguesas. Tendo ido à Espanha para apoiar Henrique IV na guerra contra os mouros de Granada, Einghen passa também por Portugal em 1457, por ter tido notícia de que Afonso $V$ se organizava para combater os mouros da África. Embora nos legue um relato mais detalhado que o de outros viajantes que passaram pela Espanha e por Portugal, quando se refere a esta nação, Einghen deixa sua ênfase recair sobre $D$. Afonso $V$ - apresentado como "príncipe gracioso, o mais determinado e mais cristão guerreiro e sensato" que ele conheceu na vida - , sobre sua corte e sobre a referida guerra que empreendia

\footnotetext{
${ }^{6}$ Viajes por España de Jorge de Einghen, del baron Leon de Rosmithal de Blatna, de Francisco Guicciardini y de Andrés Navajero, p. 111 (tradução minha).

7 Ibid., p. 106.

8 Ibid., p. 112.

${ }^{9}$ Saunders trata da importância e do peso do tráfico de escravos em Portugal e destaca que, embora grande parte do tráfico tenha sido centralizado em Lisboa, nunca o foi inteiramente. SAUNDERS, A. C. de C. M. História social dos escravos e libertos negros em Portugal (14411555). Lisboa: Imprensa Nacional Casa da Moeda, 1982, p. 31-37.

${ }^{10}$ Viajes por España de Jorge de Einghen, del baron Leon de Rosmithal de Blatna, de Francisco Guicciardini y de Andrés Navajero, p. 112-114 e 117 (tradução minha).

${ }_{11}$ FOULCHE-DELBOSC, R. Bibliographie des voyages en Espagne et en Portugal. Revue hispanique. Troisième année. Paris: Alphonse Picard et Fils: 1896, p. 18-19.
} 
contra a África. ${ }^{12}$ Lisboa aparece apenas referida como a capital do reino e há menção a "belas cidades, castelos e monastérios", mas não diz quais, nem nada específico sobre umas e outros. ${ }^{13}$

Tão poucas indicações sobre Lisboa nos relatos dos viajantes quatrocentistas, num tempo em que, juntamente com as crônicas e outros registros históricos, esses relatos começam a ser decisivos na construção da memória sobre as cidades, levam-nos a interrogar sobre o porquê de tão notável ausência, quando cidades com potencial marítimo, tão diferentes como as referidas Veneza e Gênova, ou outras como Ceuta e Constantinopla, para não falar das cidades de peregrinações - como Jerusalém, Roma ou Santiago de Compostela - são mais minuciosamente descritas por viajantes como os acima referidos ou outros de seus contemporâneos. Se é possível notar que, além da memória religiosa, são as condições comerciais e já não tanto o potencial bélico que se destacam nas menções às cidades, é também possível deduzir que Lisboa, no século XV, não gozava ainda de privilégio comercial, ${ }^{14}$ nem tampouco, como é sabido, era um destino de peregrinação religiosa ou caminho para um lugar de visitação religiosa.

Não se destacava Lisboa, do mesmo modo, como possível campo de conquista, como, por exemplo, era o caso de Ceuta neste século XV. Quando menciona tal cidade da África, o mesmo Jorge de Einghen julga importante dizer que "é uma grande cidade, cujas três partes estão cercadas de terra, e a quarta de mar, e no [seu] parecer é maior que Colônia". Além da comparação com uma célebre cidade europeia, o viajante ainda acrescenta outros dados, como as covas que ali havia e que eram "sepulturas abandonadas", e mais ênfase dá às condições de defesa dessa cidade posicionada em ponto tão estratégico: "nela se levanta também uma alta cidadela com algumas torres, e na parte inferior dessas há seteiras e há ameias na superior" e, ao seu redor, "há uma muralha de circunvalação". ${ }^{15}$

Tais capacidades defensivas, contudo, não merecem a mesma atenção de alguns viajantes não comprometidos, como Einghen ou Guicciardini, com questões políticas e que viajaram, pelo simples prazer de viajar, "por diversas partes do mundo", como foi o caso de Pero Tafur, sevilhano ${ }^{16}$ que viajou pela Itália, Palestina, Egito, Bizâncio, Turquia, Alemanha, cidades limítrofes dos Países Baixos, Polônia, Áustria e outras cidades nas imediações do Adriático e do Mediterrâneo, em meados do século XV (1436-1439). Entre detalhes e especificidades curiosos de uma ou outra cidade, mostra-se Tafur de olhos menos abertos para as condições de defesa do que para as condições de circulação de pessoas e mercadorias, e para as marcas religiosas e legendárias

12 Viajes por España de Jorge de Einghen, del baron Leon de Rosmithal de Blatna, de Francisco Guicciardini y de Andrés Navajero, 1879, p. 28 e 31 (tradução minha).

${ }^{13}$ Ibid., p. 29 e 32.

${ }^{14}$ OLIVEIRA MARQUES, A. H. Novos ensaios de história medieval portuguesa., p. 85-86.

15 Viajes por España de Jorge de Einghen, del baron Leon de Rosmithal de Blatna, de Francisco Guicciardini y de Andrés Navajero, p. 34-35 (tradução minha).

${ }^{16}$ Não há muitas certezas sobre a origem de Tafur, todavia, as diversas indicações sobre suas ligações com sevilhanos permitem deduzir que passou a maior parte de sua vida, antes de viajar, nesta cidade. TAFUR, Pero. Andanças y viajes de un hidalgo español. Marcos Jiménez de la Espada (ed.). Madrid: Miraguano/Polifemo, 1995, p. 15 e 429-430 (tradução minha). 
das cidades por onde passa. É certo, porém, que refere condições de defesa, incluindo das próprias cidades da Espanha. Sobre Málaga, por exemplo, destaca o bom posicionamento, "ainda que não tenha porto", e acrescenta várias qualidades, com ênfase sobre o fato de ser "murada" e ter "dois castelos em um canto em uma altura que por uma rua murada vão de um a outro", mas continua enfatizando que se trata de uma cidade mercandantesca, ainda dominada pelos mouros - lamenta ele. ${ }^{17} \mathrm{E}$ as condições comerciais, juntamente com as digressões sobre o passado histórico inscrito na arquitetura das cidades, vão se destacando ao longo do relato desse nobre comprometido acima de tudo em conhecer diversas partes do mundo. ${ }^{18}$ As referências arquitetônicas de fundo religioso, histórico ou mitológico, por exemplo, têm um imenso peso no relato desse viajante castelhano. Sobre Roma, por exemplo, lança mais detidamente luz, chamando atenção para a baixa densidade demográfica, se considerada sua "grandeza", mas especialmente destaca traços arquitetônicos que remetem para seu passado pagão e cristão, desde monumentos em louvor a imperadores ou sepulturas desses grandes homens, até as diversas construções religiosas, cujos traços fazem lembrar símbolos e passagens cristãs - como as relíquias de São Pedro e São Paulo, entre tantas outras referências. Esta Roma, que tinha sido a cabeça do mundo, não perdia em suas cerimônias "nada daquilo que, quando subjugava o mundo, tinha; porém [estava] em tão baixo estado que dizê-lo [seria] vergonhoso". ${ }^{19}$

Outras cidades de peregrinação também merecem referências mais precisas de viajantes, como é o caso de Santiago, por exemplo. Em cidades como essas, de que Jerusalém é o melhor exemplo, são os lugares legendários que interessam ${ }^{20}$ - como não poderia deixar de ser num tempo em que as peregrinações eram uma das principais manifestações da piedade. ${ }^{21}$ Daí que sobre Santiago, por exemplo, as indicações girem acima de tudo em torno do templo onde o santo foi enterrado. ${ }^{22}$ Ainda que visitantes como Leon Romisthal,

\footnotetext{
${ }^{17}$ Ibid., p. 19-20 (tradução minha).

18 A partir do século XIII, o que antes era visto como uma tentação pecaminosa passa gradualmente a ser bem aceito e a culpa pela curiosidade se esvai cada vez mais, assumindo os relatos uma feição de reportagem. Ver: HOWARD, D. R. Writers \& pilgrims. Medieval pilgrimage narratives and their posterity. Berkeley/Los Angeles/London: University of California Press/A Quantum Book, 1980, p. 106; CHAREYRON, N. Les pélerins de Jérusalem au Moyen Age. Paris: Imago, 2000, p. 24-25.

${ }^{19}$ TAFUR, Pero. Andanças y viajes de un hidalgo español, p. 28-31 e 32 (tradução minha).

${ }^{20}$ A topografia legendária do Evangelho marcou profundamente a piedade cristã, daí que se possa entender a importância dos deslocamentos com finalidades religiosas. Maurice Halbawchs, na sua obra em que confere primazia às representações coletivas, confere especial atenção aos lugares santos e ao seu impacto na memória coletiva, propondo que as adaptações que as referências a esses lugares sofrem se dão segundo o presente em que são interpretadas e importam não por sua origem, mas por serem uma "experiência de psicologia coletiva". HALBAWCHS, M. La topographie legendaire des évangiles en terre sainte. Etude de mémoire collective. Paris: Presses Universitaires de France, 1971. p. 7.

${ }^{21}$ SIGAL, Pierre Andre. Les marcheurs de Dieu. Pèlerinages et pèlerins au Moyen Age. Paris: Armand Colin, 1974, p. 138.

${ }^{22}$ Cf. MALEVAL, M. DO A. T. Maravilhas de São Tiago. Narrativas do Liber Sancti Jacobi - Codex Calixtinus. Niterói: Eduff, 2005.
} 
por exemplo, não se esqueçam de outros aspectos que dizem respeito à sua capacidade de defesa ou configurações gerais - como estar protegida por "uma só muralha", ser rodeada por um "amplo fosso" e coroarem "o muro torres quadradas de uma antiga fábrica" ${ }^{\prime 3}$ - 0 que realmente importa nessas cidades é o passado cristão que elas trazem à tona nas configurações arquitetônicas e em lugares especiais onde exemplos de fé ocorreram. ${ }^{24}$

Esse preâmbulo, contudo, tem como única finalidade mostrar alguns exemplos das inúmeras formas como as cidades eram observadas por visitantes no século XV e o que nelas procuravam ver homens com objetivos diferentes religiosos, políticos ou simplesmente aventurosos -, mas com um universo de expectativas comuns que lhes conduzia o olhar e definia os contornos das cidades visitadas; contornos que traduzem tanto o que se observa diretamente nelas quanto o que se esperava delas. Muitos outros exemplos poderiam ser arrolados para mostrar certa diversidade e certa unidade que caracterizam a visão dos viajantes quatrocentistas sobre as cidades do seu tempo, mas o que aqui se viu nos permite já justificar o alvo desta comunicação, que é lembrar que a história de uma cidade é feita sobretudo do que dela se disse, escreveu, pintou ou retratou, já que o que nela se viveu e se viu só é apreensível a partir dessas diversas formas como foi representada e lembrada. ${ }^{25} \mathrm{O}$ horizonte daqueles que viram, pensaram, compreenderam e expressaram as cidades, isto é, os intérpretes, tem, portanto, um peso decisivo nas imagens que ao longo dos séculos contribuíram para definir as cidades de ontem e de hoje.

Como, porém, a Lisboa dos visitantes estrangeiros por Portugal no século XV é uma Lisboa que se define apenas por impressões ou indicações gerais, como vimos anteriormente, o principal discurso que virá a configurar a Lisboa medieval é o discurso histórico dos próprios cronistas portugueses. É esse discurso que, como veremos, ajudou, através de naturalizações e idealizações como quaisquer discursos, a configurar Lisboa como "cidade grandíssima e cabeça de Portugal", ${ }^{26}$ mas uma Lisboa que, tal como a dos viajantes, ainda no

${ }^{23}$ Viajes por España de Jorge de Einghen, del baron Leon de Rosmithal de Blatna, de Francisco Guicciardini y de Andrés Navajero, p. 98 (tradução minha).

${ }^{24}$ Segundo Nicole Chareyron, deve-se a Constantino o renascimento e o estabelecimento dos lugares santos que se afirmariam como lugares de peregrinação. Peregrinações que se alimentaram dos Evangelhos canônicos e apócrifos. CHAREYRON, N. Les pélerins de Jérusalem au Moyen Age, p. 104-105.

${ }^{25} \mathrm{Um}$ dos grandes problemas que se tem colocado para o conhecimento histórico desde as últimas décadas do século XX diz respeito à relação entre a linguagem e o mundo, ou seja, acerca de como o contexto ou "mundo real" é ele mesmo textualizado em vários sentidos. A afirmação de que importa aqui o que se disse sobre as cidades justifica-se porque essas representações são muito mais do que meras impressões, são parte da própria configuração das cidades. A vida social, de um modo geral, está envolvida em "processos textuais que são frequentemente mais complicados do que a imaginação histórica está disposta a reconhecer". A própria realidade é "sempre já" implicada no problema do uso da linguagem e a verdadeira reconstrução do contexto ou de uma realidade toma lugar sobre as bases dos restos "textualizados" do passado. LACAPRA, D. Rethinking intellectual history and reading texts. In: Rethinking intellectual history: Texts, contexts, language. Ithaca, Nova Iorque: Cornell University Press, 1983, p. 26-27.

${ }^{26}$ Referência que se encontra em uma passagem em que narra uma curiosa história, ilustrativa da expectativa dos contemporâneos de Rosmisthal sobre o que se esperava e se temia das 
século XV não se anunciava como a dirigente das navegações para Oriente e Ocidente, como a virá definir o cronista Damião de Góis no século $X V I,{ }^{27}$ e como o seguirão viajantes estrangeiros, como o referido florentino Francesco Guicciardini.

A Lisboa historiada pelos cronistas portugueses do século XV não era, certamente, a mesma daquele cronista do século XVI, já que as expectativas sobre ela passam a ser muito mais amplas e abrangentes. Como sugere o cronista quinhentista, a expansão amarraria as pontas do tempo: a grandeza de um passado que os "elogios e epitáfios gravados em lápides com caracteres latinos" faziam lembrar e a fama presente dos feitos desbravadores, conjugada a uma esperança de que muito ainda estaria por vir. ${ }^{28}$ Não era, porém, apenas pelo seu caráter expansionista e por expectativas como a do português Góis arquiteto de uma Lisboa cosmopolita e um dos artífices de um Portugal protagonista dos mares - que Lisboa se distinguia, mas principalmente porque ocorre uma inversão da sua relação temporal, ou seja, enquanto a Lisboa do século XVI é paulatinamente delineada como a "rainha do oceano" e passa a ser, depois das descobertas, uma cidade da promessa e da vocação marítima, a Lisboa do século XV tinha sido construída a partir do seu papel na consolidação da soberania de Portugal. Uma sutil inversão de prioridades distancia, assim, as duas Lisboas, pois a quatrocentista é, sobretudo, voltada para dentro e para a defesa de um Portugal ameaçado por Castela, que teve um papel decisivo para garantir sua independência. Como sintetiza tão bem o infante D. João no seu discurso em defesa da guerra contra a África, foi graças à Cidade de Lisboa e à "ajuda de outros poucos bons servidores" que D. João I conseguiu reagir contra o poder da Espanha, sem a qual reação, D. Duarte "por ventura" não possuiria os reinos que possuiu. ${ }^{29}$

O reinado da Lisboa do século XV, como se vê nas crônicas portuguesas, está ligado, pois, não ao oceano, mas a causas internas, e o oceano que a banha é visto mais como obstáculo do que como caminho. ${ }^{30}$ Pintada por cronistas comprometidos em registrar o passado especificamente com a finalidade de engrandecer seus reinos e seus reis, a Lisboa que aos poucos se configura nos relatos históricos de Fernão Lopes, Gomes Eanes de Zurara, Rui de Pina e Duarte Galvão, é uma Lisboa que serve ao mesmo tempo de sede do poder e de amparo a ele. Nesse conjunto de fontes, responsável pela

\footnotetext{
viagens de além-mar. Viajes por España de Jorge de Einghen, del baron Leon de Rosmithal de Blatna, de Francisco Guicciardini y de Andrés Navajero, p. 10 (tradução minha).

${ }^{27}$ Cf. GÓIS, Damião de. Descrição da cidade de Lisboa. Trad. do texto latino, introdução e notas de José da Felicidade Alves. Lisboa: Livros Horizonte, 1988, p. 29 e 62.

${ }^{28}$ Ibid., p. 39.

${ }^{29}$ PINA, Rui de. Crônica de D. Duarte. In: Crónicas. ed. M. Lopes de Almeida. Porto: Lello \& Irmão, 1977, cap. XVII, p. 530.

${ }^{30}$ Vale aqui lembrar a metáfora de Fernando Pessoa na segunda parte do poema Mensagem, em que recorda as glórias portuguesas ultramarinas e diz que o Infante D. Henrique cumpriu a vontade divina de que o mar unisse, já não separasse.
} 
sistematização da memória e pelo estabelecimento de certo passado, ${ }^{31}$ que foi, se não o principal, um dos principais pilares para a configuração e 0 estabelecimento das origens de Portugal, ou melhor, das próprias origens da nação, ${ }^{32}$ os cronistas, menos do que descrever as cidades, mostram como estas são palco de cenas memoráveis em torno do rei e da corte régia, cenas que, naquele tempo, eram por excelência as cenas da história. ${ }^{33}$

No quadro das cidades referidas e apresentadas, Lisboa, tal como aquela dos viajantes, era já vista como a "mais principal do reino", a mais prestigiada e a que colaborava para prestigiar os próprios eventos importantes. Era, pois, muitas das vezes, a sede das cerimônias notáveis, embora houvesse ocasiões em que outras, para serem prestigiadas, eram as escolhidas. ${ }^{34} \mathrm{Em}$ caso de casamento de infantes ou de recepção de estrangeiros ilustres para realização de bodas, por exemplo, Lisboa, segundo sugere Rui de Pina, só era preterida se as circunstâncias assim o impusessem. No casamento do infante D. Afonso, filho de D. João II, por exemplo, o rei não pôde receber - como queria e como merecia a ocasião - a princesa D. Isabel de Sevilha em Lisboa, pois esta cidade, que era a "primeira", estava então marcada por uma "indisposição de saúde", a peste, e não pôde ser sede das honras prestadas aos noivos, como sonhava D. João II. ${ }^{35}$

E também não é demais lembrar exemplos de outras cerimônias que ali tiveram lugar, como aquela em que João Afonso Telo foi feito conde e armado cavaleiro. Este recebeu a "maior honra, em sua festa", como até aquele tempo não se tinha visto rei fazer a "semelhante pessoa". Tudo se fez em Lisboa, onde foram lavradas "seiscentas arrobas de cera, de que fizeram cinco mil círios e tochas", e vieram do termo de Lisboa cinco mil homens para segurarem as ditas velas. Tendo sido o auge do espetáculo quando, do mosteiro de São Domingos de Lisboa até os paços reais, por ordem do rei, ficaram dispostos "aqueles homens todos, cada um com seu círio aceso, que davam todos mui grande lume; e El-rei, com muitos fidalgos e cavaleiros, andava por entre eles, dançando e tomando sabor". ${ }^{36}$ Talvez inspirados por essa e outras cerimônias, D. João I "tinha vontade de fazer grandes festas em Lisboa para fazer seus filhos cavaleiros" e projetava "ordenar umas festas reais que [durassem] todo

\footnotetext{
${ }^{31}$ GUENÉE, B. Histoire et culture historique dans l'Occident médiéval. Paris: Editions AubierMontaigne, 1980, p. 361-367.

32 Bernard Guenée foi um dos historiadores que insistiu sobre o papel da história no estabelecimento e afirmação das origens. Propõe ele que foi a história que estimulou o sentimento de orgulho que sustentou as nações, e foi ela que ajudou a fixar e glorificar as origens que justificaram as diferenças e encorajaram as lutas nacionais. GUENÉE, B. Ocidente durante os séculos XIV e XV. Os Estados. Rio de Janeiro: Tomson Pioneira, 1971, p. 103-109.

33 É bom lembrar que a história contada na Idade Média, em especial aquela produzida no âmbito da corte, é uma história que trata do poder e dos homens que o conduzem. Cf. SERRÃO, J. V. A historiografia portuguesa. Doutrina e crítica, vol. I. Lisboa: Editorial Verbo, 1972 , p. 65-123, especialmente, p. 117.

34 LOPES, Fernão. Cronica del rei Dom João I de boa memoria. Parte Segunda, ed. William J. Entwisle. Lisboa: Imprensa Nacional Casa da Moeda, 1977, cap. XCVI, p. 208-210.

35 PINA, Rui de. Crónica de D. João II. In: Crónicas, cap. XLIV, p. 969-980.

36 LOPES, Fernão. Crónica do senhor rei Dom Pedro. Introdução de Damião Peres. Porto: Livraria Civilização, cap. XIV, p. 62.
} 
um ano". ${ }^{37}$ Festas que, contudo, não chegaram a ocorrer, dado o sonho dos infantes de conquistar Ceuta.

Essas tais cerimônias certamente contribuíam para engrandecer Lisboa, já também engrandecida pelos tesouros que ali se acumulavam. Como conta Fernão Lopes, quando D. Fernando subiu ao trono, na torre do "castelo de Lisboa foram achadas oitocentas mil peças de ouro e quatrocentos mil marcos de prata - afora moedas e outras cousas de grande valor que aí estavam". ${ }^{38}$ Do mesmo modo, era em Lisboa que se situava a Torre do Tombo, onde estava reunida a maior parte da documentação do reino. Mas a prioridade de Lisboa confirmada pelas crônicas não deve ser confundida com exclusividade, pois outras cidades foram também lugar de cerimônias de núpcias, de aclamações, de levantamentos ${ }^{39}$ e de entronizações de reis, ${ }^{40}$ de armamento de cavaleiros, de batizados, de cerimônias religiosas diversas, de recepções de figuras ilustres e de entradas régias. ${ }^{41}$ Daí que tivessem nelas lugar justas, jogos de canas, procissões, momos, banquetes, touradas e músicas, entre outros espetáculos públicos a partir dos quais o poder se fazia presente ${ }^{42} \mathrm{e}$, portanto, espetáculos de profunda eficácia simbólica no processo de ordenação social e de afirmação e encenação do poder $^{43}$ pois os súditos tinham nessa altura oportunidade de apreciar a grandeza do rei e da corte régia, ${ }^{44}$ ou melhor, era nessas ocasiões

\footnotetext{
${ }^{37}$ ZURARA, Gomes Eanes de. Crónica da tomada de Ceuta. Ed. Francisco Maria Esteves Pereira. Coimbra: Academia das Sciencias de Lisboa, cap. VIII, p. 24.

${ }^{38}$ LOPES, Fernão. Crónica do senhor rei Dom Fernando. Introdução de Salvador Dias Arnaut. Porto: Livraria Civilização, prólogo, p. 5.

${ }^{39}$ LOPES, Fernão. Cronica del rei Dom João I de boa memoria. Parte Primeira. Ed. Braamcamp Freire. Lisboa: Imprensa Nacional-Casa da Moeda, 1973, cap. CXCII, p. 372.

${ }^{40}$ PINA, Rui de. Crónica de D. João II. In: Crónicas, especialmente caps. III, IV e V, p. 899-901.

${ }^{41}$ Sobre as entradas régias em Castela, ver: DÍAS, Rosana de Andrés. Las entradas reales castellanas en los siglos XIV y XV, según las crónicas de la época. In: En la España medieval, n. 4, 1984, p. 47-62. Disponível em: http://dialnet.unirioja.es/servlet/articulo?codigo=122055. Acesso em 22/06/2010.

${ }^{42}$ Sobre o papel das cerimônias, além de Chartier (CHARTIER, Roger. A história cultural. Lisboa: Difel, 1990), que trata de como se articulam a ordem dos símbolos, das cerimônias e dos discursos no jogo do poder (p. 225), ver Rita Costa Gomes e Nieto Soria, que tratam do peso dos ritos na afirmação do poder. GOMES, Rita da Costa. A realeza: Símbolos e cerimonial. In: COELHO, Maria Helena da Cruz e HOMEM, Armando Luís de Carvalho (coord.). A Génese do Estado moderno no Portugal tardo-medievo (Sécs. XIII-XV). Lisboa: UAL, 1997, p. 201-213 (especialmente, p. 209); SORIA, Jose M. N. Cerimônias de la realeza - Propaganda y legitimación en la Castilla Trastámara. Madrid: NEREA, 1993.

${ }^{43}$ Vale lembrar aqui o clássico de Norbert Elias, (ELIAS, Norbert. A sociedade de corte. Rio de Janeiro: Jorge Zahar Ed., 2001) em que fala da importância dada ao cerimonial no desempenho da sociedade de corte.

${ }^{44}$ Bernard Guenée e Françoise Lehoux (GUENÉE, B. ; LEHOUX, F. Les entrées royales françaises de 1329 à 1515. Paris, 1968, p. 7) propõem que as entradas régias na França eram uma oportunidade de diálogo do rei e seus súditos, mas este caráter, pelo que se deduz do empenho dos governantes na preparação dos cerimoniais, pode ser estendido também a outras celebrações. Rita Costa Gomes aborda especificamente o sistema cerimonial na realeza portuguesa e seu papel, mas dá pouca atenção às entradas. GOMES, Rita da Costa. A realeza: Símbolos e cerimonial.
} 
que o rei e o poder ganhavam existência para os súditos em geral. ${ }^{45}$ Lisboa é muitas vezes referida, como, por exemplo, por ter sido o lugar onde D. Duarte foi aclamado rei, ${ }^{46}$ mas tal cerimônia ocorreu em Tomar, quando seu filho $D$. Afonso $V$ foi "posto em vestiduras reais e, bem acompanhado de todos, saiu fora ao assentamento, onde pelo Infante D. Pedro, com grande reverência, e muito acatamento, foi posto na Cadeira real". ${ }^{47}$ E D. João II, em 1477, foi elevado pela primeira vez ao trono, por recomendação de seu pai ainda vivo, ${ }^{48}$ em Santarém, e depois, em 1481, reuniu Cortes e recebeu as homenagens em Évora. ${ }^{49}$

A cidade capital, portanto, desempenha um papel histórico que muitas vezes era também desempenhado por outras cidades do reino. Todavia, isto não significa que não gozasse de mais prestígio. Além da já referida vontade de D. João II de que o casamento do seu filho fosse na principal cidade, outros indicativos apontam para sua importância. Na Crônica de D. Duarte, narra o cronista Rui de Pina que, estando em Alcochete em busca de recuperação de sua saúde, o rei da Boa Memória pede, ao sentir-se no "extremo da vida", que o encaminhem para Lisboa, pois, segundo Pina, "para tal rei como ele não convinha morrer em aldeias e desertos, mas na mais principal e na melhor casa de seus reinos". ${ }^{50}$ Tal prestígio, como sugerem os registros históricos, mostra-se também nas indicações de que ela era uma espécie de carro-chefe do que acontecia em todo o reino. Quando correu a notícia do casamento indevido de D. Fernando com D. Leonor, conta Lopes que circulou a notícia "não somente em Lisboa", como era de se esperar, "mas em Santarém, e em Alenquer, e em Tomar, e Abrantes, e outros lugares do Reino, falando as gentes deste casamento quanto Ihes parecia feio [...]". ${ }^{51}$ E não era também de se estranhar que os ingleses que vieram ajudar a terra de D. Fernando - mas que pareciam ter sido "chamados para a destruir"- fossem estabelecidos em Lisboa. ${ }^{52}$ Todavia, nenhuma impressão ou função que Ihe foi atribuída diz mais sobre o seu papel no Portugal daquele tempo do que a narrativa de Fernão Lopes sobre as atitudes de $D$. Leonor Teles para tentar amenizar a rejeição das gentes do reino à sua pessoa. A rainha, então, "porque Lisboa é principal lugar do Reino, e quem a tiver por sua entende que tem todo o Reino", mandou dar "o castelo dessa cidade ao conde D. João Afonso Telo, seu irmão; e fez que quantos grandes e bons havia na cidade, que todos fossem seus vassalos". ${ }^{53}$

Mas essa preocupação de conquistar Lisboa está ligada a outro mérito da cidade cabeça de Portugal, que, porém, não é também apenas especificidade dela. As cidades eram muitas vezes lembradas pelos cronistas no que diz respeito a questões bélicas ou a disputas de poder, pois estavam entre os bens primeiros a serem alcançados e eram elas que mais intensamente viviam a

\footnotetext{
45 GOMES, Rita da Costa. Símbolos e cerimonial., p. 207.

${ }^{46}$ PINA, Rui de. Crônica de D. Duarte. In: Crónicas, cap. II, p. 493.

${ }^{47}$ PINA, Rui de. Crônica de D. Afonso V. In: op.cit., cap. II, p. 588.

${ }^{48}$ Ibid., cap. CCII, p. 862.

${ }^{49}$ PINA, Rui de. Crónica de D. João II. In: Crónicas, cap. I, p. 894.

${ }^{50}$ PINA, Rui de. Crônica de D. Duarte. In: Crónicas., cap. I, p. 489.

${ }^{51}$ LOPES, Fernão. Crónica do senhor rei Dom Fernando, cap. LXI, p.164.

${ }^{52}$ Ibid., cap. CXXXII, p. 367.

${ }^{53}$ Ibid., cap. LXV, p. 171-173.
} 
ameaça de guerras externas e conflitos internos. Nesse sentido, Lisboa estava no topo dos interesses e na mira dos ataques. Não era, pois, de causar surpresa que o rei castelhano, D. João I, empenhado em assumir o trono de Portugal, cercasse justamente esta cidade, como ocorreu em 1384, no contexto da crise sucessória de D. Fernando - como, do mesmo modo, havia feito anteriormente D. Afonso Henriques para tomá-la aos mouros. ${ }^{54}$ Lisboa, então, sofreu todas as agruras de um cerco, segundo descreve Fernão Lopes. ${ }^{55} \mathrm{~A}$ carência generalizada de alimentos, por exemplo, condenou os moradores à degradação da fome: homens e rapazes eram encontrados mortos por se terem fartado de comer ervas e beber água, na falta de outro qualquer mantimento; dada a míngua de carne, as próprias bestas serviam de alimentos inclusive para as "grandes pessoas" da cidade; crianças pequenas esmolavam pela cidade sem conseguir muito mais do que as lágrimas daqueles a quem pediam; esforçavam-se uns para consolar os outros e remediar seu grande sofrimento; inúmeras vezes rogavam a Deus "devotadamente pelo estado da cidade"; e as agruras não ficavam por aí. Tamanhos eram os padecimentos que, de acordo com o cronista, "Deus por sua mercê quis cedo" abreviá-los, ordenando que seu "anjo da morte" espalhasse a peste entre os castelhanos. ${ }^{56}$

Essa mesma Lisboa que colaborou com D. João e que resistiu a D. João I de Castela vinha já há muito se impondo como cidade estratégica. Na Crónica de 1419, por exemplo, é narrado o empenho de D. Afonso Henriques em conquistar diversas cidades aos mouros, mas especialmente em conquistar o caminho que ligava Santarém ao mar e cujo obstáculo maior estava justamente na tomada de Lisboa. Esta cidade e as fortalezas que contribuiriam para sua proteção, Sintra, Almada e Palmela foram tomadas pelos cristãos e protegidas como convinha e como era possível na altura. ${ }^{57} \mathrm{~A}$ urbe ia, pois, aos poucos se afirmando como o carro-chefe do reino de Portugal, como a cidade que primeiramente deveria ser cuidada pelos reis, mas que nem sempre o era devidamente. Quando D. Henrique de Castela invadiu Portugal, em 1372, praticamente não encontrou resistência, pois tomou a todos de surpresa, e até mesmo Lisboa era "devassa e sem nenhum muro", não contando com outra "guarda nem defensão, salvo a cerca velha". ${ }^{58}$ Descuido tão prejudicial para o reino e tão injurioso para ele próprio que, no ano seguinte, D. Fernando se empenhou em repará-lo - mesmo a contragosto dos que julgavam excessivo o gasto com tal empreendimento -, a fim de que aquela cidade, que "era a melhor e mais poderosa de sua terra e na qual principalmente estava a perda e defesa de seu reino", fosse inteiramente cercada, com "uma boa e defensável cerca". ${ }^{59}$

${ }^{54}$ GALVÃO, D. Chronica de El-Rei D. Affonso Henriques. Lisboa: Escriptorio, 1906 (Biblioteca de Clássicos Portugueses), cap. XXXIV, p. 110-113.

${ }^{55}$ LOPES, Fernão. Cronica del rei Dom João I de boa memoria. cap. CXIV - CL, p. 236-312.

${ }^{56}$ Ibid., cap. CXLVIII e CXLIX, p. 268-273.

57 Crónica de cinco reis de Portugal. Ed. diplomática de A. Magalhães Basto. Porto: Liv. Civilização, 1945, p. 80-86; GALVÃO, D. Chronica de El-Rei D. Affonso Henriques. cap. XXXIV.

58 LOPES, Fernão. Crónica do senhor rei Dom Fernando, p. 193-194.

${ }^{59}$ Ibid., p. 233-234. 
Mas qual o interesse de pensar essas imagens mais ou menos difusas da capital portuguesa por cronistas do século XV? Tais imagens, pode-se dizer, ensinam, ao mesmo tempo, sobre o estar no mundo dos homens que escreveram a história na Idade Média e sobre o passado que eles selecionaram para tornar lembrado, e que acabaram por efetivar como o "verdadeiro" passado em seus textos. ${ }^{60}$

Nesse trabalho de reconstrução das cidades através da linguagem - já que as "coisas do mundo não podiam ser tocadas" senão através dela, e já que os eventos em si não são apreensíveis ${ }^{61}-$, o componente humano de Lisboa é o que mais se destaca. Quando o povo se manifestou contra o referido casamento de $\mathrm{D}$. Fernando com $\mathrm{D}$. Leonor Teles - mulher que, além de já ser casada, não era Infante e, portanto, não era merecedora de tamanha honra como aquela -, "juntaram-se em magotes", tentando encontrar formas para evitar o desaire. "E entre os que principalmente disto trabalharam, foram os da cidade de Lisboa". ${ }^{62}$ Os de Lisboa, da mesma forma que virão, mais tarde, garantir junto com D. João I a independência de Portugal, já aqui se empenham para reverter uma situação que, segundo sugere Fernão Lopes, já sabiam que traria consequências nefastas.

Pouco depois, é o apoio desses mesmos de Lisboa que leva o Mestre de Avis a voltar atrás na sua decisão de partir de Portugal, quando ouve de Álvaro Vasques que não poderia, na Inglaterra, "cobrar outra tão boa cidade, por força de armas, como a cidade de Lisboa", e ainda mais uma cidade em que "oferecem os moradores dela a vos servir, e dar quanto têm, até morrerem por vos ajudar?"163 Com "tais razões" como essas, o Mestre resolve ficar e dar continuidade ao que a história veio a celebrizar como o culminar da independência de Portugal. Desde esses primeiros passos, pois, a "principal" cidade do reino vai protagonizando os acontecimentos que levaram D. João I ao poder $\mathrm{e}$, consequentemente, os acontecimentos que, no século $\mathrm{XV}$, foram logicamente organizados para fazerem crer que o caminho que Portugal tomava com D. João I era um caminho que já se anunciava, e que era o melhor que poderia ser. $\mathrm{O}$ desempenho do coletivo de Lisboa, pois, além de remontar aos descontentamentos com D. Leonor Teles e com a aclamação de D. Beatriz e seu marido D. João de Castela como reis de Portugal, culmina no reconhecimento do Mestre de Avis como rei. Da reação inicial contra a possibilidade de ver Portugal, "que tantas cabeças e sangue custou a ganhar quando foi tomado aos

${ }^{60}$ COLEMAN, Janet. Ancient and medieval memories. Studies in the reconstruction of the past. New York: Cambridge University Press, 1992, p. XV. A autora, no seu livro, propõe que se tome "como evidências do passado, textos do passado, relatos de outrora acerca de como os homens construíram narrativas sobre como foi para eles estar no mundo" (tradução minha).

${ }^{61}$ Ibid., p. XVI. Segundo a referida autora, as "teorias medievais de memória são, em parte, teorias da reconstrução. Isto porque aprender a ler e escrever depende há muitos séculos dos textos de lógica e de gramática da antiguidade clássica, que efetivamente argumentaram que as coisas no mundo, às quais a linguagem e o pensamento se referem, não poderiam ser "tocadas", exceto através da mediação dos signos linguísticos ou mentais. Assim, a análise de um texto que era um fragmento preservado do passado no presente só podia ser um exame de formas coerentes de falar gramaticalmente e logicamente sobre experiências, ao invés de um exame dos próprios eventos (tradução minha).

62 LOPES, Fernão. Cronica del rei Dom João I de boa memoria, cap. LX, p. 103.

${ }^{63}$ Ibid., cap. XXII, p. 39. 
mouros ", praticamente doado por D. Fernando, ${ }^{64}$ até a nomeação do Mestre de Avis como "Regedor e Defensor do Reino", Lisboa alcança uma participação mais efetiva nos destinos do reino, conduzindo as demais cidades. ${ }^{65}$ Muitos outros exemplos da atuação de cidades em favor ou contra o Mestre poderiam ser citados, mas nenhuma atuação é tão notável quanto a do coletivo de Lisboa, do qual o cronista Fernão Lopes revela as inquietações, temores e capacidade de articulação e intervenção nos rumos do poder.

E não foi somente nessa altura crucial que as gentes de Lisboa são destacadas como agentes da história. Na altura da morte do rei D. Duarte, depois do insucesso de Tânger $^{66}$, Lisboa insurge contra outra Leonor, a Leonor de Aragão, esposa de D. Duarte. Os alvoroços na cidade se sucedem e mais uma vez ela atua, apoiada por outras vilas e cidades do reino - com destaque para o Porto -, como interlocutora privilegiada no processo que garante o regimento ao infante D. Pedro. ${ }^{67}$ É também Lisboa, juntamente com Coimbra, que tem papel ativo nos conflitos entre este infante e $\mathrm{D}$. Afonso $\mathrm{V}$. ${ }^{68}$ Mas essas atuações marcantes, vale destacar, não são as únicas atribuídas ao agente designado "os de Lisboa". Estes aparecem em algumas participações menores, como avisos, pedidos ao rei e como expectadores de cenas diversas; atuações, portanto, menos marcantes, mas que igualmente compõem seu papel na sociedade portuguesa da Idade Média. ${ }^{69}$

Lisboa, porém, igualmente se distingue pelo seu desempenho administrativo, tendo cumprido um papel de ordenação do território juntamente com Coimbra, Santarém e Porto. A cidade que, entretanto, dadas as condições históricas do momento, aparece na crônica de 1419 como lugar de parada do ainda príncipe $D$. Afonso Henriques para encaminhar o erário ${ }^{70}$ e para decidir sobre os rumos de sua ação militar ${ }^{71}$ - atividades indissociáveis da função régia medieval - é Coimbra. Mas, no tempo de D. Fernando, Lisboa já aparece mais nitidamente contemplada no seu potencial de centro decisório. Na Crônica de $D$. Fernando, pode-se notar que a cidade concentrava boa parte dos tesouros do reino, mas também que as rendas da sua alfândega - junto com as da alfândega da cidade do Porto - eram parte significativa da arrecadação régia. ${ }^{72}$ Dali, do mesmo modo, D. Fernando, depois de ter feito várias ordenações para regimento de seu reino em Évora, delibera acerca de formas de aproveitamento da terra, propondo inclusive a convocação dos pedintes para trabalhar em

\footnotetext{
${ }^{64}$ LOPES, Fernão. Crónica do senhor rei Dom Fernando, cap. CLXXV, p. 484.

${ }^{65}$ Cf. LOPES, Fernão. Cronica del rei Dom João I de boa memoria, cap. II-III, p. 7-10.

${ }^{66}$ ZURARA, Gomes Eanes de. Crónica do conde D. Duarte de Menezes. Ed. Larry King. Lisboa: Universidade Nova de Lisboa, 1978, cap. XXV, pp. 108-109. Cf. PINA, Rui de. Crônica de D. Duarte. In: Crónicas, cap. XLIII, pp. 573-574.

${ }^{67}$ PINA, Rui de. Crónica de D. Afonso V. In: Crónicas, cap. XXIV-XXXVI, p. 611-625.

${ }^{68}$ Ibid., cap. CX-CXXII, p. 730-748.

${ }^{69}$ Cf. GALVÃO, D. Chronica de El-Rei D. Affonso Henriques, cap. LV, p. 157-158.

${ }^{70}$ Crónica de cinco reis de Portugal, cap. 8, p. 60.

${ }^{71}$ Cf. Ibid., cap. 34, p. 114-117.

72 LOPES, Fernão. Crónica do senhor rei Dom Fernando, cap. LXXXIX, p. 237-241.
} 
tarefa que demandava tantos braços. ${ }^{73}$ Deliberações não menos importantes que aquelas que D. João I aí toma acerca do desempenho da justiça no reino, depois de vê-lo "desabafado dos feitos da guerra", e também acerca da tomada de Ceuta. ${ }^{74}$

Entre essas e outras imagens e funções que não temos espaço para mapear aqui, Lisboa vai aos poucos se configurando. Como outras cidades, suas grandezas e belezas estavam associadas acima de tudo àquilo que nelas tinha ocorrido ou à forma como seus habitantes atuaram. Portanto, a ordenação e os edifícios da cidade só são mencionados ou descritos, na história registrada pelos cronistas quinhentistas, se relacionados a um evento, como o sepultamento de relíquias, o albergamento de cortes, a sujeição aos ataques, a acolhida de festas, entre outros. Mesmo que partilhe funções semelhantes com outras cidades e divida espaço com elas, a futura "rainha do oceano" é apresentada, no Quatrocentos, através de seu passado remoto e do mais recente, como a cabeça do reino e depois da nação. Viajantes estrangeiros, de forma mais ligeira, e cronistas portugueses, de forma mais minuciosa, são peças-chave na configuração da imagem de Lisboa e de uma história de Lisboa. Uma imagem e uma história que não devem ser ingenuamente opostas a um conjecturado real, mas antes devem ser vistas como formas textuais de falar de forma lógica sobre experiências difusas.

Compreender a linguagem e os códigos com que esses homens do século XV se referiam ao mundo que se apresentava a eles como não textual é, sem dúvida, um caminho frutífero para entender o jogo entre o ideal e o real que compõe qualquer história. Se os limites da nossa capacidade intelectiva não nos permitem falar sobre as realidades às quais as palavras se referem, talvez não seja de todo absurdo conjecturar que o que cronistas e viajantes disseram sobre Lisboa não deixou de alimentar, no tempo deles e nos posteriores, certa confusão entre experiências narradas e experiências vivenciadas. ${ }^{75}$

\section{Sobre a autora}

Susani Silveira Lemos França é doutora em Cultura Portuguesa pela Universidade de Lisboa e Professora de História Medieval da Universidade Estadual Paulista (UNESP), Campus de Franca. Os seus estudos, atualmente, enfatizam o discurso histórico e dos viajantes dos séculos XIII, XIV e XV. É autora de "Os reinos dos cronistas medievais" (Annablume, 2006), tradutora e organizadora de "Viagens de Jean de Mandeville" (EDUSC, 2007) e organizadora de "As cidades no tempo" (Olho d'Água, 2005).

\footnotetext{
${ }^{73}$ Cf. LOPES, Fernão. Cronica del rei Dom João I de boa memoria. Parte Segunda, cap. CCI, p. 451-453.; ZURARA, Gomes Eanes de. Crónica da tomada de Ceuta, cap. XVI-XX, p. 51-66.

${ }^{74}$ LOPES, Fernão. Cronica del rei Dom João I de boa memoria. Parte Segunda, cap. CCI, pp. 451-453 e ZURARA, Gomes Eanes de. Crónica da tomada de Ceuta, cap. XVI-XX, p. 51-66.

${ }^{75} \mathrm{Cf}$. COLEMAN, Janet. Ancient and medieval memories, pp. XVI-XVII.
} 